\title{
BROOKHGWEN
}

NATIONAL LABORATORY

BNL-114331-2017-JA

\section{Seven years of aerosol scattering hygroscopic growth measurements from SGP: factors influencing water uptake}

\author{
A. Jefferson, T. Watson
}

Accepted for publication in J. Geophys. Res. Atmos.

August 2017

Environmental \& Climate Science Dept.

Brookhaven National Laboratory

\section{U.S. Department of Energy USDOE Office of Science (SC), Biological and Environmental Research (BER) (SC-23)}

\footnotetext{
Notice: This manuscript has been authored by employees of Brookhaven Science Associates, LLC under Contract No. DE-SC0012704 with the U.S. Department of Energy. The publisher by accepting the manuscript for publication acknowledges that the United States Government retains a non-exclusive, paid-up, irrevocable, worldwide license to publish or reproduce the published form of this manuscript, or allow others to do so, for United States Government purposes.
} 


\section{DISCLAIMER}

This report was prepared as an account of work sponsored by an agency of the United States Government. Neither the United States Government nor any agency thereof, nor any of their employees, nor any of their contractors, subcontractors, or their employees, makes any warranty, express or implied, or assumes any legal liability or responsibility for the accuracy, completeness, or any third party's use or the results of such use of any information, apparatus, product, or process disclosed, or represents that its use would not infringe privately owned rights. Reference herein to any specific commercial product, process, or service by trade name, trademark, manufacturer, or otherwise, does not necessarily constitute or imply its endorsement, recommendation, or favoring by the United States Government or any agency thereof or its contractors or subcontractors. The views and opinions of authors expressed herein do not necessarily state or reflect those of the United States Government or any agency thereof. 

factors influencing water uptake

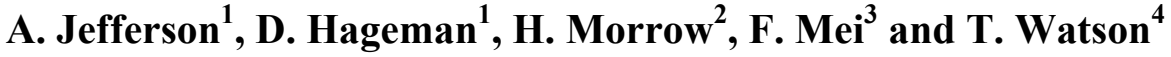

${ }^{1}$ Cooperative Institute of Research in the Environmental Sciences, University of Colorado, Boulder.

${ }^{2}$ Science and Technology Corporation, Boulder, CO.

${ }^{3}$ Pacific Northwest National Laboratory, Richland, WA.

${ }^{4}$ Brookhaven National Laboratory, Upton, NY.

15 Corresponding author: Anne Jefferson (anne.jefferson@,colorado.edu)

\section{Key Points:}

- We present uncertainty analysis of the calculated, RH-dependent, aerosol scattering coefficient for two algorithms.

- The aerosol hygroscopic growth at SGP exhibited a strong seasonal dependence, driven mostly by change in the aerosol chemical composition.

- We present a method for evaluating RH-driven changes in the aerosol phase. 


\begin{abstract}
Long-term measurements of changes in the aerosol scattering coefficient hygroscopic growth at the U.S. Department of Energy Southern Great Plains site provide information on the seasonal as well as size and chemical dependence of aerosol water uptake. Annual average sub $10 \mathrm{um} f R H$ values (the ratio of aerosol scattering at $85 \% / 40 \% \mathrm{RH}$ ) were 1.75 and 1.87 for the gamma and kappa fit algorithms, respectively. The study found higher growth rates in the winter and spring seasons that correlated with a high aerosol nitrate mass fraction. $f R H$ exhibited strong, but differing, correlations with the scattering

10 Ångström exponent and backscatter fraction, two optical size-dependent parameters. The aerosol organic fraction had a strong influence on $f R H$. Increases in the organic mass fraction and absorption Ångström exponent coincided with a decrease in $f R H$. Similarly, $f R H$ declined with decreases in the aerosol single scatter albedo. Uncertainty analysis of the fit algorithms revealed high uncertainty at low scattering coefficients and slight increases in uncertainty at high RH and fit parameters values.
\end{abstract}




\section{Introduction}

Aerosol forcing of climate is largely two fold, extinction of solar radiation or direct forcing and changes in cloud droplet formation or indirect forcing. An integral factor regulating these forcings is the aerosol water content. Globally averaged, water comprises half of the aerosol mass (Textor et al., 2006). Nguyen et al. (2016) calculated the water ambient mass fractions across 21 continental sites to vary from $3.7 \%$ in urban Beijing to $79 \%$ in rural Finland. In a high RH marine environment water can enhance the dry aerosol surface area and hence optical depth by a factor of 4 (Lewis and Schwartz, 2004). In addition to optical depth, RH-modulated aerosol water uptake impacts the aerosol size, lifetime, asymmetry parameter and single scatter albedo. In a microphysical context, changes in relative humidity can modify the gas to aerosol partitioning of semi-volatile compounds. In addition, water influences aqueous oxidation reactions within the aerosol, that in turn alter the aerosol mass, optical properties and cloud droplet activation (Gund et al., 1991,. Lewandowski et al., 2015).

Model constraint of the aerosol extinction increase from water uptake depends on several factors. An AeroCom comparison of aerosol forcing models found a large diversity in the predicted aerosol water content. Much of this discrepancy stems from the high variability of ambient RH and aerosol composition but also from limited data on aerosol hygroscopic growth (Kinne et al., 2006; Textor et al., 2006). Field measurements of RH-dependent aerosol optical depth exemplify this variability and highlight the difficulty in modeling aerosol hygroscopic growth. Aircraft measurements of aerosol properties over a polluted, urban region during DISCOVER-AQ attributed $88 \%$ of the extinction variability to aerosol loading at low ambient $\mathrm{RH}$ and only $10 \%$ to aerosol water uptake (Beyersdorf et al., 2016). However, this same study revealed that when RH exceeded $60 \%$, the aerosol hygroscopic growth accounted for $62 \%$ of the extinction spatial variability and $95 \%$ of the diurnal variability.

Climate models rely heavily on remote sensing measurements for data input. The RH fields and aerosol hygroscopic growth are tightly coupled in many remote-sensing retrievals. Aerosol size-dependent retrievals from aerosol optical depth (AOD), such as the Ångström exponent, aerosol index and aerosol fine mode fraction, all depend on the aerosol water content. In their assessment of aerosol hygroscopic growth between remote sensing and in situ aircraft measurements Ziemba et al. (2013) found good agreement between vertically-resolved ambient extinction from the High-Spectral Resolution Lidar (HSRL) and a single-parameter empirical estimate of the hydrated nephelometer aerosol scattering coefficient. While ground-based, in situ, humidified nephelometer measurements lack vertical resolution; in a well-mixed atmosphere they can validate the column-integrated, aerosol remote sensing retrievals. More importantly, surface measurements of nephelometer scattering as a function of RH can validate model predictions and remote sensing measurements associated with seasonal changes in and cross-correlations between the aerosol optical properties.

As the resolution of remote sensing measurements increases, more sophisticated and detailed probing of small-scale, atmospheric processes become possible. High RH environments, particularly in cloud outflow, have become useful to studying cloud- 
aerosol interactions. For these studies, high-resolution remote sensing lidars (Yang et al., 2014 and Bar-Or et al., 2012) and AOD from geostationary satellites (Saide et al., 2014) probe small regions of the cloud edge where the RH gradient is steep (Bar-Or et al., 2012). Better aerosol hygroscopic growth information would improve these algorithms as well as those that predict CCN (cloud condensation nuclei) from aerosol dry extinction, AOD or aerosol index (Shinozuka et al., 2015 and Jefferson, 2010). The quality of these remote sensing retrievals depends on an ability to separate meteorological fields from aerosol optical properties.

Radiative forcing model uncertainty could be significantly reduced and remotesensing algorithms improved with observational constraints of the aerosol water uptake. Analysis of aerosol hygroscopic growth in relation to aerosol optical and chemical properties helps improve aerosol-typing schemes that serve as input to satellite and surface AOD algorithm retrievals. In addition, algorithm tests of aerosol properties with and without column water vapor can improve model resolution that may be obscured by temporal and spatial variation of water fields. To this end, this study represents longterm scattering hygroscopic growth measurements that provide a regional aerosol climatology that spans seasons, source emission regions, $\mathrm{RH}$ and aerosol composition.

Here, we present long-term measurements of aerosol scattering hygroscopic growth from the Southern Great Plains (SGP) site in Lamont, OK, operated by the Dept. of Energy Atmospheric Radiation Measurement (ARM) program. These are hydration measurements that scan the aerosol sample RH from low to high values, nominally 40 $85 \%$. The aerosol in this region is an aged aerosol of mostly organic composition that is weakly perturbed by urban sources (Zhang et al., 2013, Sherman et al., 2015). Initial hygroscopic scattering enhancement measurements at the SGP site began in 1998 and have been operated near continuously to the present date. Sheridan et al. [2001] presented results from the first year of operation. This paper evaluates the record from 2009 to 2015 , a time when the system configuration and measurement method were consistent. The overview includes

- An evaluation of the measurement uncertainty and conditions that produce the most reliable data;

- Temporal trends and variability of $f R H$ with other aerosol optical properties and

- A discussion on the role of aerosol phase and measurement conditions

\section{Measurements and Methods}

\subsection{Sampling system and instruments}

The U. S. Department of Energy, Atmospheric Radiation (ARM), Southern Great 40 Plains (SGP) facility is located in north central Oklahoma at a latitude of $36^{\circ} 36^{\prime} \mathrm{N}$, longitude of $97^{\circ} 29^{\prime} \mathrm{W}$, and an altitude of $315 \mathrm{~m}$ asl. The site is located in an agricultural region with mostly wheat, corn, alfalfa and hay crops. The closest urban centers are Witchita, KS $113 \mathrm{~km}$ north and Oklahoma City, OK $136 \mathrm{~km}$ south from the site. 
The aerosol instrumentation is housed in a trailer with a community sample inlet. The aerosol inlet is a $21.4 \mathrm{~cm}$ ID stainless steel pipe with a rain hat. Flow through the stack is $\sim 800 \mathrm{lpm}$. Aerosol is sampled from a $244 \mathrm{~cm}$ long, $5.1 \mathrm{~cm}$ outer diameter, stainless steel tube, positioned in the center of the larger stack. Flow through the inner tube is maintained at $150 \mathrm{lpm}$. The flow passes through a splitter, which separates the sample flow into 5, $30 \mathrm{lpm}$ flows. One of these $30 \mathrm{lpm}$ flows passes through a switched impactor that alternates the aerosol size between sub $10 \mathrm{um}$ and sub $1 \mathrm{um}$ aerodynamic particle diameter every 30 minutes. Downstream of the impactors the sample flow splits between a Radiance particle soot absorption photometer (PSAP) and 2 TSI (model 3563) nephelometers operated in series. Insulation, heaters and PID controllers regulate the RH at the base of the main aerosol sample tube, impactor inlet and the inlet of the first nephelometer to an RH of $40 \%$ or less. Sheridan et al. [2001] give a detailed overview of the Aerosol Observing System (AOS) instrumentation and operation.

The TSI ingregating nephelometers measure the aerosol total scattering $\left(7-170^{\circ}\right)$ and backscattering $\left(90-170^{\circ}\right)$ coefficients at 450,550 and $700 \mathrm{~nm}$ radiation. The values of the aerosol absorption coefficient used in calculation of the aerosol single scattering albedo are from the Radiance PSAP, which operates at nominal wavelengths of 467,530 and 660 $\mathrm{nm}$ radiation. The $530 \mathrm{~nm}$ absorption coefficient was wavelength corrected to $550 \mathrm{~nm}$ to coincide with the nephelometer scattering coefficient. Corrections based on light truncation in the nephelometer and aerosol scatter from the PSAP filter were performed (Anderson and Ogren, 1998, Bond et al., 1999 and Ogren, 2010). Discussion of uncertainty in the nephelometer scattering coefficients and in the PSAP absorption coefficient can be found in Anderson et al.,[1999] and Heintzenberg et al., [2006], Sheridan et al., [2005], Virkkula et al., [2005] and most recently in Sherman et al., [2015].

The Aerodyne Aerosol Chemical Speciation Mass spectrometer (ACSM) measures the non-refractory, sub-micron aerosol mass concentration. The measured ion mass components are $\mathrm{NH}_{4}{ }^{+}, \mathrm{NO}_{3}{ }^{-}, \mathrm{SO}_{4}{ }^{2-}, \mathrm{Cl}^{-}$, and total organics. Data were screened by the aerosol mass scattering efficiency to eliminate times with low ion detection efficiency. Parworth et al. [2015] discuss the ACSM operation at SGP in further detail.

\subsection{Humidified nephelometer measurements}

The humidifier was designed for robust, continual operation with little technical support other than adding water to a reservoir. So to produce a dry, reference scattering coefficient yet also minimize evaporation of semi-volatile compounds such as ammonium nitrate and weak organic acids, the air sample is actively dried to a minimum RH of $40 \%$ at the dry nephelometer inlet. During winter months with low dew point temperatures, the minimum RH inside the dry nephelometer will drop as low as $5 \%$, adding some ambiguity to the hygroscopic growth curves as weak acids volatilize and inorganic salts potentially change phase from liquid to solid.

The humidifier rests between the two nephelometers and consists of two concentric tubes with a PID controlled heater around the outer tube. Distilled water from a reservoir circulates between the outer stainless steel tube and an inner porous PTFE 
(polytetrafluoroethylene) tube. The RH of the sample air, flowing down the center PTFE tube, is ramped in hourly cycles with a maximum RH at the half hour. The control RH sensor (Vaiasla model HMP60) is located at the exit of the humidified nephelometer. The humidifier scans the hydration branch of the aerosol scattering coefficient. Nominal RH values at the exit of humidified nephelometer cycle from 40 to $85 \% \mathrm{RH}$ and vary with the ambient dew point. The relative humidity inside the nephelometer is calculated from the instrument dew point measured with the Vaisala RH/T sensor at the wet nephelometer exit and the internal wet nephelometer temperature. The highest relative humidity of the sample air is at the wet nephelometer exit. The system Vaisala RH/T sensors are calibrated annually on site using a Thunder Scientific Model 2500 humidity generator, calibrated to NIST standards.

A least-square Levenburg-Marquardt algorithm fits the data to equation 1 (Section 2.3), hereafter referred to as the gamma algorithm, for the 26 minute scan of each aerosol size. The parameterization shown in equation 4 (Section 2.3, kappa algorithm) is fit to the data using a bivariate, linear fit routine with error in both coordinates. The fit criteria limit the scans to minimum scattering coefficients of $10 \mathrm{Mm}^{-1}, 14$ or more data points and a minimum $\mathrm{RH}$ between $40-60 \%$ for the $\mathrm{RH}$ scans in the humidified nephelometer.

\subsection{Aerosol scattering hygroscopic growth algorithms}

Past measurements of the RH dependence of the aerosol scattering coefficient date back to Pueschel et al. [1969] and have been done for multiple regions using varying techniques as well as equations to parameterize the growth behavior (Covert et al., 1972, Kotchenruther et al.,1998, Carrico et al., 2007, Gasso et al., 2000, Quinn et al., 2005, Fierz-Schmidhauser et al., 2010, Titos et al., 2014 and Zieger et al., 2013). Aerosol which are metastable or are on the upper branch of the hygroscopic growth hysteresis curve for an inorganic salt will typically follow a simple power law fit as described by Kasten in 1969.

$$
\sigma_{\mathrm{w}}\left(\mathrm{RH}_{\mathrm{w}}\right) / \sigma_{\mathrm{o}}\left(\mathrm{RH}_{\mathrm{o}}\right)=\mathrm{a}\left(1-\mathrm{RH}_{\mathrm{w}} / 100\right)^{-\gamma}
$$

Here, $\gamma$ and "a" are the fit parameters and $\sigma_{o}\left(\mathrm{RH}_{\mathrm{o}}\right)$ is the aerosol scattering coefficient held at a reference humidity and $\sigma_{\mathrm{w}}\left(\mathrm{RH}_{\mathrm{w}}\right)$ is the scattering coefficient at a specified higher or "wet" RH. The parameter "a" normalizes the scattering growth, typically to an $\mathrm{RH}$ of $40 \%$ and $\gamma$ indicates the magnitude of the hygroscopic increase in the scattering coefficient. A common term to compare this growth across studies, geographic regions as well as fit equations is $f R H$ or the ratio of wet/dry scattering with a reference RH of $40 \%$ and a wet $\mathrm{RH}$ of $85 \%$. For an ambient aerosol, $f R H$ varies from 1.0 for hygrophobic soot aerosol to as high as $\sim 4$ for sea salt aerosol (Randles et al., 2004).

Brock et al. [2016] proposed an alternative algorithm for extinction hygroscopic growth based on the aerosol diameter hygroscopic growth parameter, $\kappa_{d}$. 


$$
g f(D)=\left(1+\kappa_{d} \frac{\mathrm{RH}}{100-\mathrm{RH}}\right)^{1 / 3}
$$

Here $g f(D)$ is the diameter growth factor. The aerosol scattering hygroscopic growth is derived from the cube of equation 2 or volume growth factor and the Mie scattering equation below.

$$
\sigma=\int \frac{\pi}{4} D^{2} Q(n, D) N(D) d D
$$

$\mathrm{Q}$ is the scattering efficiency; $\mathrm{n}$ is the refractive index and $\mathrm{N}$ the number concentration. For particle size ranges smaller than the wavelength of visible light used in these measurements $(550 \mathrm{~nm})$, changes in Q can be approximated as linear with D such that $\sigma \propto D^{3}$. Based on the Mie equation above the aerosol scattering hygroscopic growth can be expressed in terms of a volume growth.

$$
\frac{\sigma_{w}}{\sigma_{d}}=\left(1+\kappa_{s c a} \frac{R H}{100-R H}\right)
$$

20 The $\kappa_{s c a}$ of equation 4 is proportional to $\kappa_{\mathrm{d}}$ of equation 2 but not equivalent. Kuang et al. [2017] estimate $\kappa_{\text {sca }}: \kappa_{\mathrm{d}}$ from a site in the North China Plains to range between 0.55-0.81, based on aerosol $f R H$ measurements and $\kappa_{\mathrm{d}}$ simulated from measured aerosol size distributions and $f R H$. Brock et al. [2016] measured a similar ratio of 0.6-1.0 from their measurements in the Southeastern US. This equation may not hold for super micron aerosol and needs evaluation in this size range.

The correlation between the two algorithms varies with $\mathrm{RH}$ and scattering values such that one fit equation may perform better over differing RH range, scattering, aerosol type, modal size distribution or growth rate. The algorithm performance depends on how well the aerosol growth pattern within a given $\mathrm{RH}$ range conforms to the fit as well as the total fit uncertainty with respect to the combined $\mathrm{RH}$ and aerosol scattering uncertainties.

\section{Calculation of uncertainty}

35 An informed application of the $f R H$ fits requires knowledge of the fit uncertainty over a range of conditions such as loading, $\mathrm{RH}$ and growth rate. The most common application of the scattering hygroscopic fit parameter in models and in instrument comparisons is the calculation of aerosol extinction or scattering at an ambient $\mathrm{RH}$ from the dry measurement. With this in mind, the uncertainty in the scattering hygroscopic growth is

40 expressed in terms of the calculated scattering coefficient at a given RH or wet scattering coefficient.

$$
\sigma_{w}\left(R H_{w}\right)=\sigma_{d}\left(R H_{d}\right)\left[\frac{\left(1-\frac{R H_{w}}{100}\right)}{\left(1-\frac{R H_{o}}{100}\right)}\right]^{-\gamma}
$$




$$
\sigma_{w}\left(\mathrm{RH}_{w}\right)=\sigma_{d}\left(\mathrm{RH}_{d}\right)\left[b+\kappa_{s c a}\left(\frac{\mathrm{RH}_{w}}{100-\mathrm{RH}_{w}}\right)\right]
$$

$\mathrm{RH}_{\mathrm{d}}$ and $\mathrm{RH}_{\mathrm{w}}$ are the relative humidity values from the dry, reference nephelometer and ambient (wet) conditions, respectively.

Application of the fit parameters to determine an ambient scattering coefficient requires normalization to a reference scattering coefficient at a given $\mathrm{RH}_{\mathrm{d}}$. Both the kappa and gamma algorithms assume a continuously increasing scattering coefficient with increasing $\mathrm{RH}$. The $\mathrm{RH}$ at which the aerosol scattering coefficient displays a measureable increase will vary with the aerosol composition and phase. We define $\mathrm{RH}_{\mathrm{o}}$ as the maximum $\mathrm{RH}$ below which no measureable scattering growth with $\mathrm{RH}$ is observed. $\mathrm{RH}_{\mathrm{o}}$ is set to $40 \%$ in the uncertainty calculations. We replaced the kappa fit offset value of 1 with a second fit parameter $b$ for the kappa equation. Tying the fit to a value of 1 at $\mathrm{RH}_{\mathrm{w}}=0$ implies a continuous growth in the scattering coefficient with $\mathrm{RH}$ throughout the $\mathrm{RH}$ range. Although ambient aerosols contain some water at low $\mathrm{RH}$ values, an increase in scattering from water uptake isn't typically observed at RH values below $30-40 \%$. Note that at $\mathrm{RH}_{\mathrm{o}}, b=1-\kappa_{\text {sca }}\left(\mathrm{RH}_{\mathrm{o}} /\left(100-\mathrm{RH}_{\mathrm{o}}\right)\right)$.

The uncertainty is determined by summing the errors of the individual sources in quadrature. We set $\mathrm{RH}_{\mathrm{o}}$ to $40 \%$ for the uncertainty calculations. The uncertainty associated with equation 5 is given below.

$$
\frac{\delta \sigma_{w}}{\sigma_{w}}=\sqrt{\left(\frac{\partial \sigma_{w}}{\partial \sigma_{d}} \delta \sigma_{d}\right)^{2}+\left(\frac{\partial \sigma_{w}}{\partial R H_{w}} \delta R H_{w}\right)^{2}+\left(\frac{\partial \sigma_{w}}{\partial \gamma} \delta \gamma\right)^{2}}
$$

The uncertainty of equation 6 involves substituting $\kappa$ for $\gamma$ in equation 7 and adding a $4^{\text {th }}$ term for uncertainty associated with the $b$ parameter. Uncertainty in $b$ is taken as the standard deviation of this uncertainty in fits of the data. The average standard deviation in $b$ for the kappa fits is $+/-0.035$ for fits with an $r^{2}$ correlation coefficient greater than 0.3 .

The uncertainty in the relative humidity measurement was taken as the reported uncertainty from Vaisala of 3\%. The uncertainty in the nephelometer wet and dry scattering coefficients stems from five sources; noise, instrument drift, angular scattering truncation, calibration and STP corrections. These uncertainties for 1-minute signal integration as a function of the scattering coefficient are reported in Anderson et al., [1999].

The standard deviations of the fit parameters $\gamma$ and $\kappa$ were calculated numerically from a Monte Carlo (MC) simulation of equations 1 and 4. The kappa fit $b$ parameter was set equal to 1 for the MC simulation in order to evaluate the role of scattering and $\mathrm{RH}$ on $\kappa$ uncertainty and for comparison of this uncertainty with $\gamma$. In the MC simulation $\sigma_{d}$ was varied for 1,10 and $100 \mathrm{Mm}^{-1}$. The MC method uses random sampling to simulate the probability distribution of data about a mean value. As a first approximation, the only factors contributing to the uncertainty inputs in the simulation are the nephelometer noise and $\mathrm{RH}$. We ran 1000 fit simulations for each set of input parameters using a random 
sequence of numbers generated over the nephelometer range of noise for a given dry scattering coefficient and a 3\% uncertainty in RH.

5 The results of the MC simulation are given in Table 1 . The $\gamma$ fit values of $0.2,0.5$ and 0.8 were used in the MC simulation, which correspond to $f R H(85 \% / 40 \%)$ values of 1.3 , 2.0 and 3.0, respectively. $\kappa$ fit values were set to $0.05,0.2$ and 0.4 , which correspond to $f R H(85 \% / 40 \%)$ values of $1.2,1.9$ and 2.6 , respectively. The MC simulation used an RH range between $40 \%-85 \%$. Using a lower or higher RH range didn't significantly change the calculated uncertainty of the fit parameters. The most notable result of the simulation is the high standard deviation (std.dev.) at low scattering coefficients. Table 1 lists the standard deviation of the calculated fit parameter in the MC simulation with fit value and scattering coefficient. Both $\gamma$ and $\kappa$ uncertainty values decrease with increased aerosol scattering. Unlike $\gamma$, which is relatively constant with the fit parameter value, the $\kappa$ uncertainty increases with $\kappa$. The standard deviation in $\gamma$ has a strong dependence on the aerosol scattering coefficient, highlighting the difficulty in fitting a power law function to noisy data.

Table 1. Monte Carlo simulated uncertainties in $\mathrm{Mm}^{-1}$ for gamma and kappa algorithm fit parameters for dry scattering coefficients

\begin{tabular}{l|ccc}
\hline & \multicolumn{3}{|c}{ Scattering Coefficient $\mathbf{~ M m}^{-\mathbf{1}}$} \\
\hline Fit Parameter & 1 & 10 & 100 \\
\hline kappa 0.05 & 0.04 & 0.00 & 0.00 \\
kappa 0.2 & 0.05 & 0.01 & 0.01 \\
kappa 0.4 & 0.09 & 0.02 & 0.02 \\
\hline gamma 0.2 & 0.32 & 0.03 & 0.01 \\
gamma 0.5 & 0.32 & 0.03 & 0.01 \\
gamma 0.8 & 0.30 & 0.03 & 0.01 \\
\hline
\end{tabular}


Table 2. Wet scattering coefficients, and standard and percent errors in the wet scattering coefficient as a function of RH and dry scattering coefficient $\left(\sigma_{\mathrm{d}}, \mathrm{RH}=40 \%\right)$ for gamma and kappa fit algorithms.

\begin{tabular}{|c|c|c|c|c|c|c|c|c|c|}
\hline \multirow{2}{*}{$\begin{array}{l}\sigma_{\mathrm{d}}=1 \\
\text { Gamma }\end{array}$} & \multicolumn{3}{|c|}{ Wet scattering $\mathrm{Mm}^{-1}$} & \multicolumn{3}{|c|}{ Absolute error $\mathrm{Mm}^{-1}$} & \multicolumn{3}{|c|}{ Percent error } \\
\hline & $45 \% \mathrm{RH}$ & $60 \% \mathrm{RH}$ & $85 \% \mathrm{RH}$ & $45 \% \mathrm{RH}$ & $60 \% \mathrm{RH}$ & $85 \% \mathrm{RH}$ & $45 \% \mathrm{RH}$ & $60 \% \mathrm{RH}$ & $85 \% \mathrm{RH}$ \\
\hline 0.2 & 1.0 & 1.1 & 1.3 & 1.4 & 1.4 & 1.8 & 133.0 & 133.6 & 140.2 \\
\hline 0.5 & 1.0 & 1.2 & 2.0 & 1.4 & 1.6 & 2.8 & 133.0 & 133.6 & 140.2 \\
\hline 0.8 & 1.1 & 1.4 & 3.0 & 1.4 & 1.9 & 4.3 & 133.0 & 133.6 & 139.4 \\
\hline$\sigma_{d}=10$ & & & & & & & & & \\
\hline Gamma & $45 \% \mathrm{RH}$ & $60 \% \mathrm{RH}$ & $85 \% \mathrm{RH}$ & $45 \% \mathrm{RH}$ & $60 \% \mathrm{RH}$ & $85 \% \mathrm{RH}$ & $45 \% \mathrm{RH}$ & $60 \% \mathrm{RH}$ & $85 \% \mathrm{RH}$ \\
\hline 0.2 & 10.2 & 10.8 & 13.2 & 2.0 & 2.1 & 2.6 & 19.2 & 19.3 & 19.6 \\
\hline 0.5 & 10.4 & 12.2 & 20.0 & 2.0 & 2.4 & 3.9 & 19.2 & 19.2 & 19.7 \\
\hline 0.8 & 10.7 & 13.8 & 30.3 & 2.1 & 2.7 & 6.0 & 19.2 & 19.3 & 19.8 \\
\hline$\sigma_{d}=100$ & & & & & & & & & \\
\hline Gamma & $45 \% \mathrm{RH}$ & $60 \% \mathrm{RH}$ & $85 \% \mathrm{RH}$ & $45 \% \mathrm{RH}$ & $60 \% \mathrm{RH}$ & $85 \% \mathrm{RH}$ & $45 \% \mathrm{RH}$ & $60 \% \mathrm{RH}$ & $85 \% \mathrm{RH}$ \\
\hline 0.2 & 101.8 & 108.4 & 132.0 & 9.8 & 10.4 & 12.8 & 9.6 & 9.6 & 9.7 \\
\hline 0.5 & 104.4 & 122.5 & 200.0 & 10.0 & 11.8 & 19.5 & 9.6 & 9.6 & 9.8 \\
\hline 0.8 & 107.2 & 138.3 & 303.1 & 10.4 & 13.5 & 30.6 & 9.7 & 9.8 & 10.1 \\
\hline$\sigma_{d}=1$ & & & & & & & & & \\
\hline Карра & $45 \% \mathrm{RH}$ & $60 \% \mathrm{RH}$ & $85 \% \mathrm{RH}$ & $45 \% \mathrm{RH}$ & $60 \% \mathrm{RH}$ & $85 \% \mathrm{RH}$ & $45 \% \mathrm{RH}$ & $60 \% \mathrm{RH}$ & $85 \% \mathrm{RH}$ \\
\hline 0.05 & 1.0 & 1.1 & 1.3 & 1.39 & 1.43 & 1.74 & 133.1 & 133.2 & 135.2 \\
\hline 0.2 & 1.2 & 1.3 & 2.1 & 1.55 & 1.73 & 2.87 & 133.1 & 133.2 & 134.7 \\
\hline 0.4 & 1.3 & 1.6 & 3.3 & 1.77 & 2.14 & 4.43 & 133.2 & 133.5 & 135.6 \\
\hline$\sigma_{d}=10$ & & & & & & & & & \\
\hline Kappa & $45 \% \mathrm{RH}$ & $60 \% \mathrm{RH}$ & $85 \% \mathrm{RH}$ & $45 \%$ RH & $60 \% \mathrm{RH}$ & $85 \% \mathrm{RH}$ & $45 \% \mathrm{RH}$ & $60 \% \mathrm{RH}$ & $85 \% \mathrm{RH}$ \\
\hline 0.05 & 10.4 & 10.8 & 12.8 & 2.00 & 2.07 & 2.57 & 19.2 & 19.2 & 20.0 \\
\hline 0.2 & 11.6 & 13.0 & 21.3 & 2.24 & 2.53 & 4.90 & 19.3 & 19.4 & 23.0 \\
\hline 0.4 & 13.3 & 16.0 & 32.7 & 2.58 & 3.17 & 8.25 & 19.4 & 19.8 & 25.3 \\
\hline$\sigma_{d}=100$ & & & & & & & & & \\
\hline Kappa & $45 \% \mathrm{RH}$ & $60 \% \mathrm{RH}$ & $85 \% \mathrm{RH}$ & $45 \% \mathrm{RH}$ & $60 \% \mathrm{RH}$ & $85 \% \mathrm{RH}$ & $45 \% \mathrm{RH}$ & $60 \% \mathrm{RH}$ & $85 \% \mathrm{RH}$ \\
\hline 0.05 & 104.1 & 107.5 & 128.3 & 9.98 & 10.34 & 14.00 & 9.6 & 9.6 & 10.9 \\
\hline 0.2 & 116.4 & 130.0 & 213.3 & 11.33 & 13.01 & 33.64 & 9.7 & 10.0 & 15.8 \\
\hline 0.4 & 132.7 & 160.0 & 326.7 & 13.33 & 17.09 & 61.93 & 10.0 & 10.7 & 19.0 \\
\hline
\end{tabular}


Table 2 shows the calculated wet scattering values and associated uncertainties calculated from equation 3 . The reported values are segregated by $\sigma_{\mathrm{d}}(1,10$ and 100$), \% \mathrm{RH}(45,60$ and 85$)$, $\gamma(0.2,0.5$ and 0.8$)$ and $\kappa(0.05,0.2$ and 0.4$)$. In general the calculated uncertainties increase with $\% \mathrm{RH}, \kappa$ and $\gamma$ and $\sigma_{\mathrm{d}}$. The relative percent uncertainty decreases with increases in $\sigma_{\mathrm{d}}$. The kappa algorithm has a considerably higher sensitivity to RH than that of gamma. For the gamma equation, uncertainty in $\sigma_{\mathrm{d}}$ dominates the total uncertainty for all $\mathrm{RH}$ and gamma values. For the kappa equation, uncertainty in $\sigma_{\mathrm{d}}$ is overridden by that of $\mathrm{RH}$ for $\sigma_{\mathrm{d}}=100 \mathrm{Mm}^{-1}$ and $85 \% \mathrm{RH}$.

The high uncertainty, particularly at low scattering coefficients, highlights the difficulty in interpreting these measurements, under clean conditions such as those in polar, marine or high altitude locations. In these cases analysis of the long-term trends and variances of hygroscopic growth with other aerosol properties may be a more reliable predictor of aerosol scattering increase with RH. The uncertainties listed in Table 2 set lower and upper limits of hygroscopic growth estimates for remote-sensing retrievals and model simulations. The multiple RH values, aerosol loadings and fit parameters help place boundaries on these estimates for a variety of conditions.

Our uncertainty analysis and normalizations don't account for measurement-specific conditions. Aerosol transmission loss in the humidifier will decrease the kappa fit value linearly such that a $5 \%$ aerosol loss will result in a $5 \%$ measured decrease in $\mathrm{\kappa}$ and $b$. This adjustment needs to be applied uniquely to each measurement system. Linear offsets to the wet scattering coefficient from aerosol losses don't affect the $\gamma$ fit value. RH gradients or an ill-defined RH inside the nephelometer measurement cavity will add uncertainty. The magnitude of this bias under varying measurement conditions is under investigation.

\section{Results}

\subsection{Temporal variability and aerosol composition}

Table 3 reports statistics on the sub $10 \mathrm{um}$ and sub $1 \mathrm{um}$ hygroscopic growth parameters with season. The kappa $f R H$ values are $3-8 \%$ higher than the gamma values. The standard deviations of both fits are comparable as are the chi square goodness of fit values. Average $f R H$ chi-square fit values of the two fits are both $2.1 \mathrm{e}-3$ for sub $10 \mathrm{um}$ aerosol data at $550 \mathrm{~nm}$. The kappa chisquare value has a lower standard deviation of $4.7 \mathrm{e}-3$ compared to that of the gamma fit of $6.0 \mathrm{e}-$ 3. For comparison the mean $r^{2}$ values for the kappa least square fit is $0.83 \pm 0.21$. As there is little difference between the seasonal statistics between the kappa and gamma algorithms, we only show trends and variances associated with the gamma fits in the figures. The monthly variability in both aerosol size ranges in Figure 1 and Table 3 show slightly lower values during the summer months. Sherman et al. [2016] note that transport to the site varies seasonally with winds predominately from the south during the summer, a region that includes Oklahoma City. Figure 2 shows wind rose plots of the $f R H$ values with season. During winter there is a higher frequency of winds from the N-NW than other seasons; the direction of Wichita, KS and a large agricultural region. Winds from the S-SE are more prevalent from spring to fall. Note that $f R H$ values vary little with wind sector for any given season. 
Table 3. Mean (standard deviation) aerosol hygroscopic growth parameters, $f R H$, and gamma $(\gamma)$

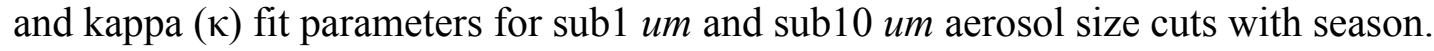

\begin{tabular}{c|c|c|c|c|c}
\hline Parameter & Spring (MAM) & Summer (JJA) & Fall (SON) & Winter (DJF) & Annual \\
\hline$f R H(\gamma)$ sub $u m$ & $1.91(0.46)$ & $1.74(0.30)$ & $1.85(0.42)$ & $1.96(0.41)$ & $1.87(0.41)$ \\
\hline$f R H(\gamma)$ sub 10um & $1.80(0.39)$ & $1.65(0.27)$ & $1.72(0.38)$ & $1.82(0.37)$ & $1.75(0.37)$ \\
\hline$\gamma$ sub um & $0.45(0.16)$ & $0.39(0.12)$ & $0.42(0.16)$ & $0.47(0.16)$ & $0.44(0.16)$ \\
\hline$\gamma$ sub 10 um & $0.41(0.15)$ & $0.35(0.12)$ & $0.37(0.16)$ & $0.42(0.15)$ & $0.39(0.15)$ \\
\hline$f R H(\kappa)$ sub um & $2.00(0.36)$ & $1.88(0.26)$ & $1.91(0.40)$ & $2.11(0.34)$ & $1.98(0.36)$ \\
\hline$f R H(\kappa)$ sub 10 um & $1.89(0.35)$ & $1.76(0.26)$ & $1.78(0.37)$ & $2.00(0.35)$ & $1.87(0.35)$ \\
\hline$\kappa$ sub um & $0.24(0.10)$ & $0.20(0.06)$ & $0.21(0.10)$ & $0.26(0.09)$ & $0.23(0.09)$ \\
\hline$\kappa$ sub 10 um & $0.21(0.09)$ & $0.17(0.06)$ & $0.18(0.09)$ & $0.23(0.09)$ & $0.20(0.09)$ \\
\hline
\end{tabular}

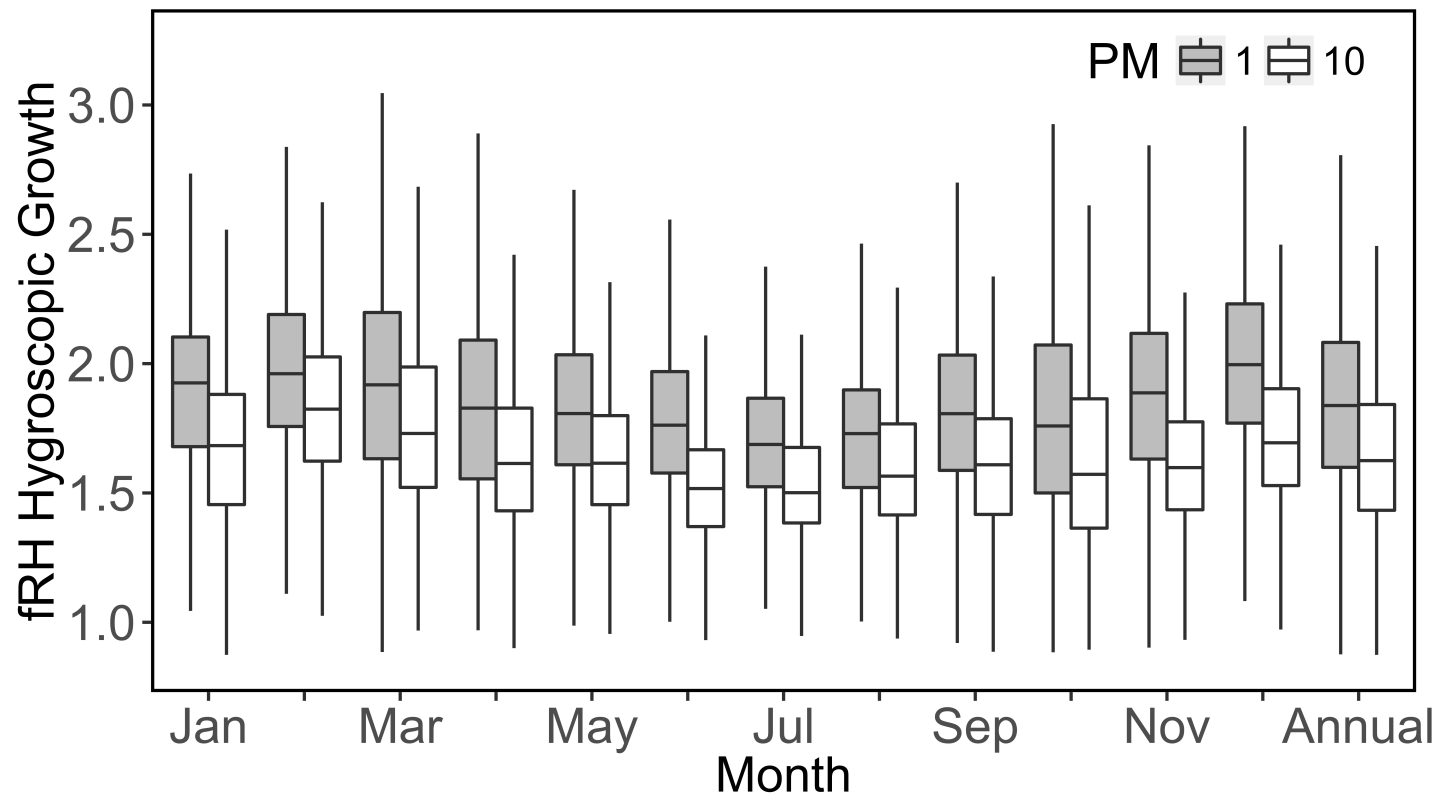

Figure 1. Box and whisker plot showing the 5, 25, 50, 75 and $95^{\text {th }}$ percentiles of the sub um and sub $10 \mathrm{um}$ aerosol $f R H$ using the gamma fit at SGP from 2009 to 2015. 


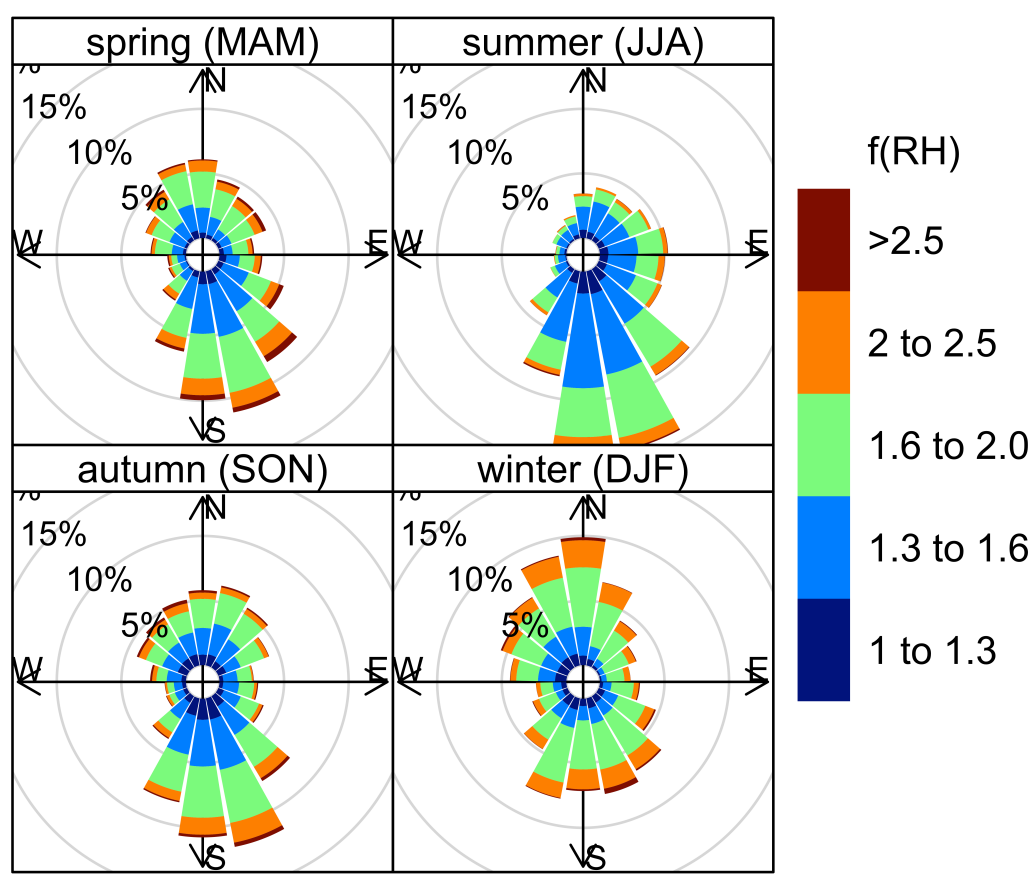

Figure 2. Seasonal wind rose plots depicting seasonal $f R H$ values with wind direction.

\subsection{Variance of $f R H$ with aerosol composition}

The seasonal variation in $f R H$ is reflected in changes in the hydrophilic, inorganic composition of the PM1 aerosol. On average organics, sulfate, nitrate and ammonium comprise over $98 \%$ of the non-refractive aerosol mass, with equivalent ratios of $\mathrm{NH}_{4}{ }^{+}$to $\mathrm{SO}_{4}{ }^{2-}$ plus $\mathrm{NO}_{3}{ }^{-}$ near 1, indicating a mostly neutral aerosol (Parworth et al., 2015). $f R H$ values are highest in winter and correlate with the nitrate ion mass concentration. The NMF (nitrate mass fraction) is highest in the cold winter and spring months when the nitrate vapor pressure is low and soil denitrification is high, particularly of unplanted fields or those fertilized in the fall (Paul and Zebarth, 1997). During winter, a shallow inversion layer and low wind speeds keep aerosol and other pollutants near the surface, resulting in a higher aerosol loading than other seasons (Sherman et al., 2015). While the $\mathrm{SO}_{4}{ }^{2-}$ mass concentration has little seasonal variability, the SMF (sulfate mass fraction) is higher in summer when the NMF is low. The summer months have the lowest $f R H$ values and also the highest aerosol organic mass fraction (OMF) (Parworth et al., 2015).

Past studies found a strong correlation between $f R H$ and the OMF that varies with aerosol type (Quinn et al., 2005 and Beyersdorf et al., 2016). Figure 3 shows the correlation between $\gamma$ and the organic mass fraction (OMF) of the non-refractive aerosol mass measured with an aerosol mass spectrometer from 2012-2014 at SGP. Data is colored by the mass fraction of nitrate and sulfate ions. Three distinct modes of aerosol hygroscopic growth behavior with OMF are apparent; 1) a low rate of increase in $\gamma$ with declining OMF when the nitrate mass fraction 
(NMF) is high and the OMF is low 2) a higher rate of increase in $\gamma$ with declining OMF in when the sulfate mass fraction (SMF) is high and 3) a large range of $\gamma$ values when the OMF is high

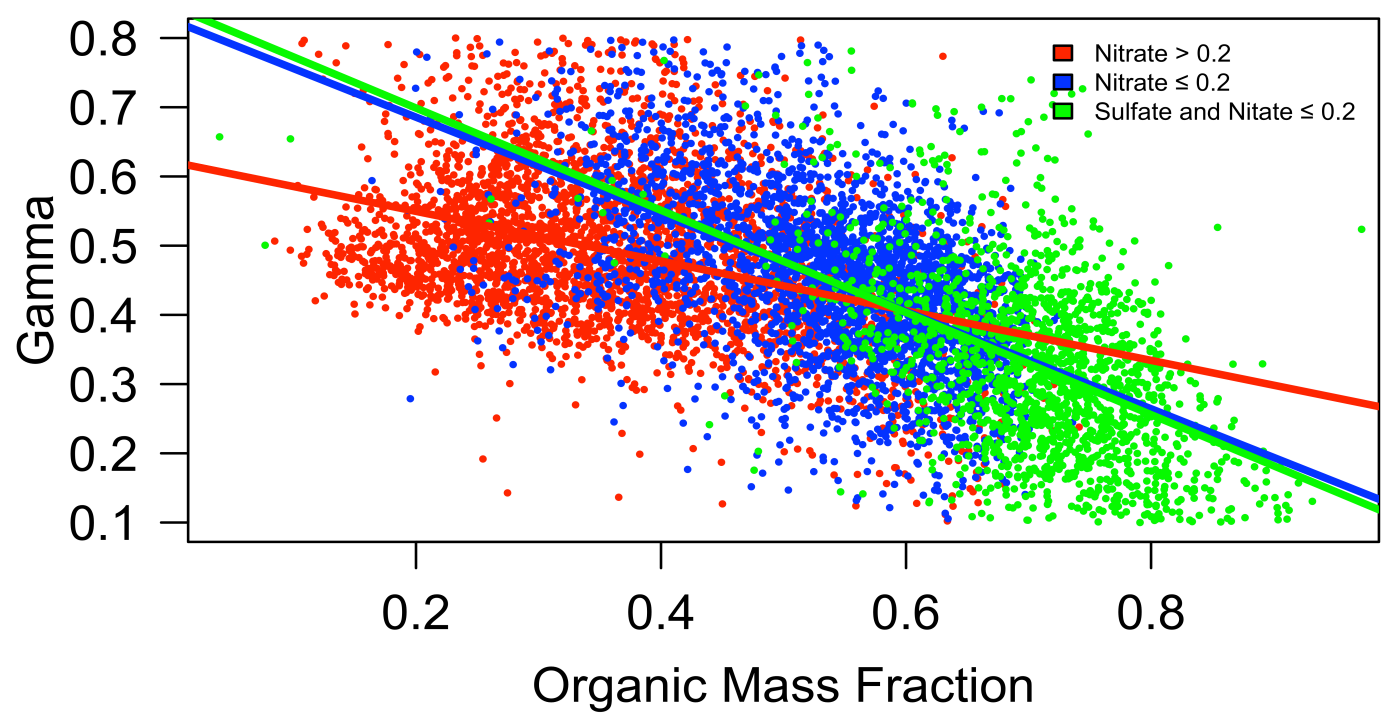

Figure 3. Variation of the gamma fit parameter with aerosol organic mass fraction and colored by nitrate and sulfate mass fraction amounts. Red and blue fit lines correspond to data with similar color. The green fit line is for the entire data set.

and the NMF and SMF are both low. The linear fits for these 3 variances of $\gamma$ vs. OMF with NMF range from -0.36 at high NMF to -0.66 for when the NMF and $\mathrm{SMF}<0.2$. We intentionally limit the gamma range of the plot to reduce the contribution of outliers that may represent smoke at low gamma or fresh sulfate aerosol formation at high gamma. As the NMF is highest in winter and spring and SMF is higher in summer, the $\gamma$ behavior with respect to the OMF varies seasonally. Similar measurements of $\gamma$ vs OMF report slopes of -0.3 to -0.5 in polluted regions and -0.7 in a marine environment (Quinn et al., 2005, Massoli et al., 2009, and Beyersdorf et al., 2016).

A remarkable feature of Figure 3 is the wide range of $\gamma$ values for $\mathrm{OMF}>0.7$. Using Positive Matrix Factorization (PMF) Parworth et al. [2015] categorized the organic aerosol mass composition into more or less oxidized and biomass burning components. Variation in the relative mass fractions of these organic components between seasons likely contributed to the variability in $\gamma$ at high OMF. Not enough data was available to compare $\gamma$ to the level of organic aerosol oxidation. Smoke aerosol, particularly aged smoke from long-range transport, could be a factor in the large variance of gamma at high aerosol OMF. Jing et al. (2017) report that potassium salts prevalent in smoke aerosol make a significant contribution to organic aerosol hygroscopic growth. A known controlled burn of an adjacent field to SGP on July 17, 2015 had gamma values of 0.2 and 0.3 over the 2 one-hour episodes, corresponding to $f R H$ values of 1.32 and 1.5 , respectively. For this particular event, fresh smoke aerosol likely had a high enough inorganic composition to significantly influence the aerosol hygroscopicity. 
Aerosol size also plays a role in the scattering hygroscopic growth variance with the OMF. Figure 4 highlights this correlation and shows the size-dependent, aerosol, hygroscopic growth with respect to the organic mass content. Larger aerosols with lower backscatter fractions (BSF) are confined to lower OMF and higher $\gamma$ values. The high nitrate and sulfate mass fractions of this larger, more hygroscopic aerosol may reflect an aged aerosol that has undergone secondary gas and aqueous phase oxidation processes. Smaller aerosol with higher backscatter fractions were concentrated at OMF values higher than 0.5 and exhibited a high range of $\gamma$ values from 0.1 to about 0.6 . Typically, smaller aerosols represent fresh emissions with a high organic content. Figure 4 shows a more varied small particle composition. The broad range of small particle hygroscopic growth at $\mathrm{OMF}>0.5$ may reflect variability in the organic aerosol oxidation state with more oxidized organics at higher $\gamma$ values or, as already discussed, the presence of inorganic potassium salts in smoke aerosol.

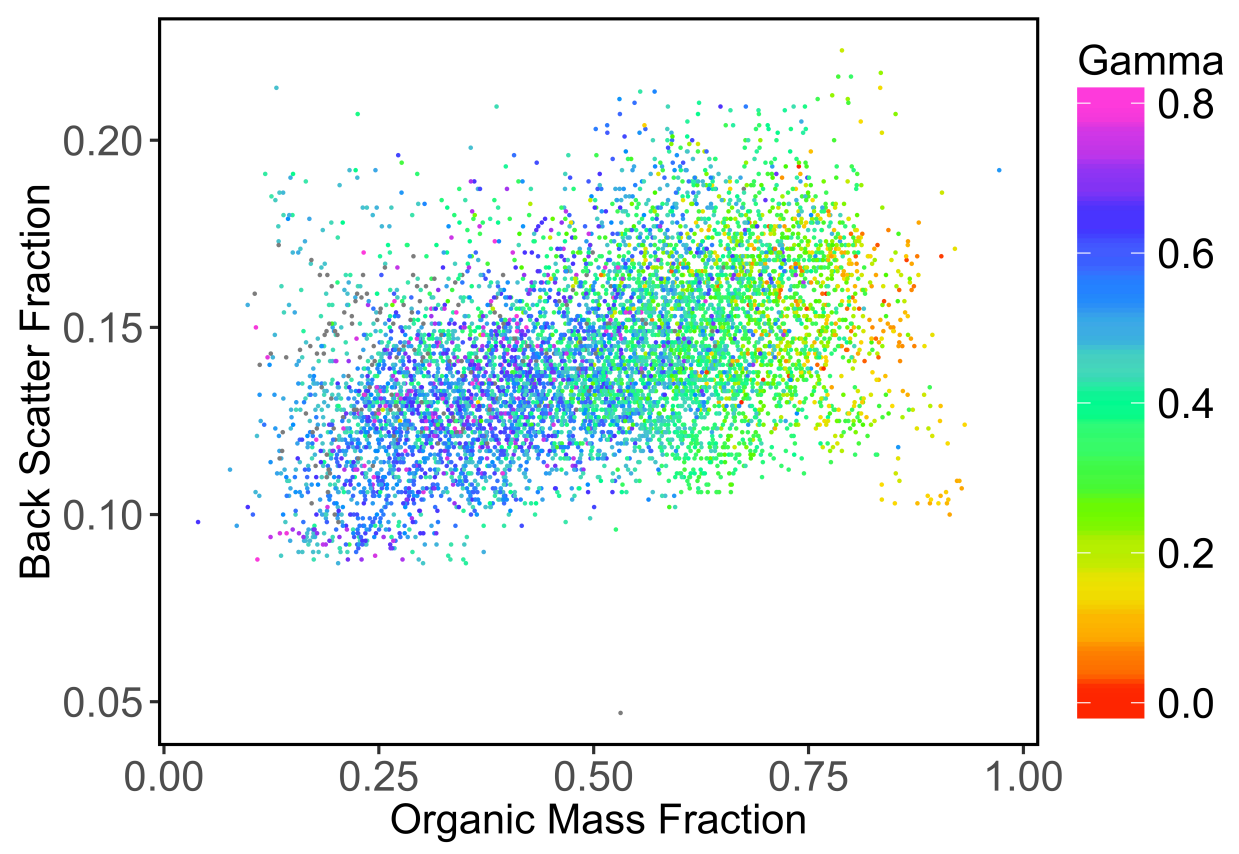

Figure 4. Sub 1 um aerosol backscattering fraction at $550 \mathrm{~nm}$ vs organic mass fraction from ACSM.

\subsection{Systematic variability with aerosol optical properties}

Figure 5 shows the $f R H$ variance with the intensive aerosol optical properties; scattering and absorption Ångström coefficients, backscatter fraction and single scattering albedo. The solid black lines show the systematic relationships between the aerosol optical properties and aerosol hygroscopicity. Both the aerosol single scatter albedo (SSA) and absorption Ångström exponent (AAE) are measures of aerosol elemental (EC) and organic brown (OC) carbon absorption. The mass absorption efficiency of OC increases at shorter visible wavelengths, resulting in higher AAE values (Barnard et al., 2008). Because non-absorbing aerosol coatings can enhance this wavelength dependence (Lack and Cappa, 2010), AAE is only a rough proxy of the organic aerosol content. SSA represents the relative aerosol scattering to extinction such that lower values indicate a stronger absorption and thus higher OC and EC content. Sherman et al. (2015) show that the AAE declines with increasing SSA, indicating a lower contribution of OC relative 
to EC at high SSA. As shown in Figures $5 \mathrm{a}$ and $5 \mathrm{~b} f R H$ increases with decreasing AAE (brown carbon) and increasing SSA (lower total carbon absorption). The correlation of $f R H$ to aerosol AAE and SSA affirms the relationship with the ACSM chemistry data in Figure 3 of a declining aerosol hygroscopic growth with increasing organic mass fraction. The probability distribution of points (dotted lines) show an AAE peak probability at $\sim 1.45$, indicating a moderate influence of absorbing organics. The SSA peak probability at 0.93 and relatively narrow range of values indicate the presence of a highly scattering aerosol at SGP with a moderate to low concentration of absorbing carbon.

Normally, aerosol EC absorption is constant across the visible spectrum with an AAE of $\sim 1$. However, aerosol coatings that form an outer shell around a dark EC core can preferentially focus certain wavelengths by acting as a wave-guide, an effect known as "lensing". Lack and Cappa (2010) predict values of AAE $<1$ in their model of clear coatings on an EC core for aerosol in the larger end of the accumulation mode with particles diameters $>150 \mathrm{~nm}$. Here, low values of AAE $<1$ at SGP are associated with high SSA values as well as larger accumulation mode particles with low BSF and low OMF values. As seen in Figure 5b, AAE $<1$ have a relatively high hygroscopicity with $f R H$ values of $\sim 1.9$. The low AAE values possibly indicate an absorption enhancement of longer wavelengths due to a clear aerosol coating. However, the lensing effect is difficult to separate from filter artifacts. Measurements of aerosol gas phase absorption could give further insight on the role of coatings and aerosol absorption.

The aerosol scattering Ångström exponent and backscatter fraction are two optical properties that decrease with increasing aerosol size. These two parameters often anitcorrelate, particularly if the aerosol has a bimodal distribution (Schuster et al., 2006). Figures 5c and 5d show plots of the hygroscopic growth parameter increasing with the scattering Angström exponent (SAE) and decreasing with the backscatter fraction (BSF). Here, $f R H$ exhibits differing size-dependent behavior with SAE and BSF at SGP. These size-dependent aerosol parameters represent different regions of the aerosol accumulation mode. The BSF is sensitive to size changes of smaller diameter particles, whereas SAE for the given wavelength pair $(550 \mathrm{~nm} / 700 \mathrm{~nm})$ is more representative of the upper size range of the aerosol accumulation mode and the super um, coarse mode. A previous study of the hygroscopic diameter growth, $g R H$, found the aerosol water uptake at SGP increased with aerosol size up to $0.3 \mathrm{um}$ and then decreased for larger particles (Gasparini et al., 2006b). The $0.3 \mathrm{um}$ diameter peak in $g R H$ and decline at larger diameters reflects the changing composition and hygroscopic growth of two modes in a bimodal aerosol size distribution. This bimodal behavior shows up in the differing size-dependent, hygroscopic growth behavior of the BSF and SAE parameters. 

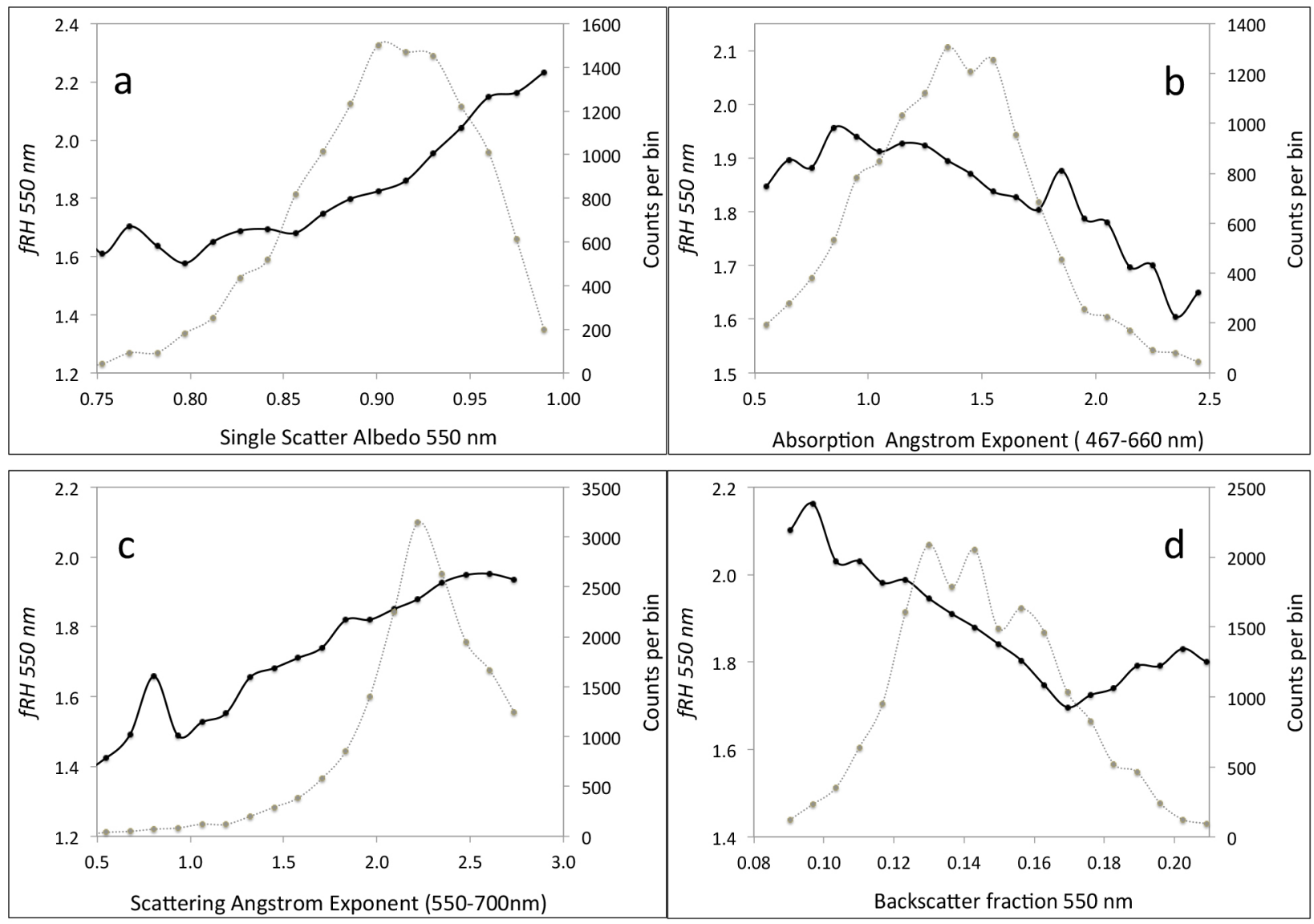

Figure 5. Plots of binned $f R H$ versus dry, intensive, aerosol optical properties (solid line) and the probability distributions of the intensive properties (gray line). Intensive properties are (a) single scatter albedo at $550 \mathrm{~nm}$, (b) absorption Ångstrom exponent for the 467:530 nm wavelength pairs, (c) scattering Ångstrom exponent for the 450:700 nm wavelength pairs, and (d) the backscatter fraction at $550 \mathrm{~nm}$.

\subsection{Variance of hygroscopic growth with ambient relative humidity}

The median ambient relative humidity over the measurement period was $63 \%$ with a lower $25^{\text {th }}$ quartile of $45 \%$ and an upper $75^{\text {th }}$ quartile of $79 \%$. The ambient RH at SGP exhibits little seasonal variation. Figure 6 shows the dependence of $f R H$ for sub $10 \mathrm{um}$ aerosol at $550 \mathrm{~nm}$ on the ambient RH. On average, $f R H$ for sub $10 \mathrm{um}$ aerosol increases from about 1.4 to about 1.9 as the ambient RH increased from 40 to $80 \%$. The dotted line of the $f R H$ distribution with RH shows that most of the measurements occur when the ambient RH is between $20-80 \%$. The ambient RH affects the aqueous phase chemistry within aerosols, the particle viscosity and also the gas to aerosol partitioning of chemical species; three factors that influence aerosol hygroscopic growth. The aerosol mass fractions of inorganic species exhibited little correlation with the ambient $\mathrm{RH}$, while the OMF slightly declined with an increase in ambient $\mathrm{RH}$. In contrast, the mass loadings of nitrate, sulfate and ammonium increased with ambient RH in accordance with the reduced vapor pressure with increasing RH of gas phase ammonia, sulphuric and nitric acid (Marti et al., 1997; Stelson and Seinfeld, 1982). The ambient RH has a weak influence on the relative fractions of inorganic and organic aerosol composition. The increase in 
aerosol hygroscopicity with ambient RH may reflect the oxidation level of organic aerosol species. More aerosol chemistry data with resolved organic oxidation level would help discern the reason for the $f R H$ and ambient RH correlation.

In addition to heterogeneous oxidation of gas phase species, in-cloud oxidation will enhance the aerosol sulfate, nitrate and oxidized organic mass fractions. Low-level cloud coverage and cloud probability increase with the ambient RH at SGP with the highest cloud probability at RH values between $75-85 \%$ (Kennedy et al., 2010). In-cloud oxidation may contribute to not only the increase in $f R H$ with $\mathrm{RH}$ but also the prevalence of bimodal aerosol size distributions at SGP (Gasparini et al., 2006b).

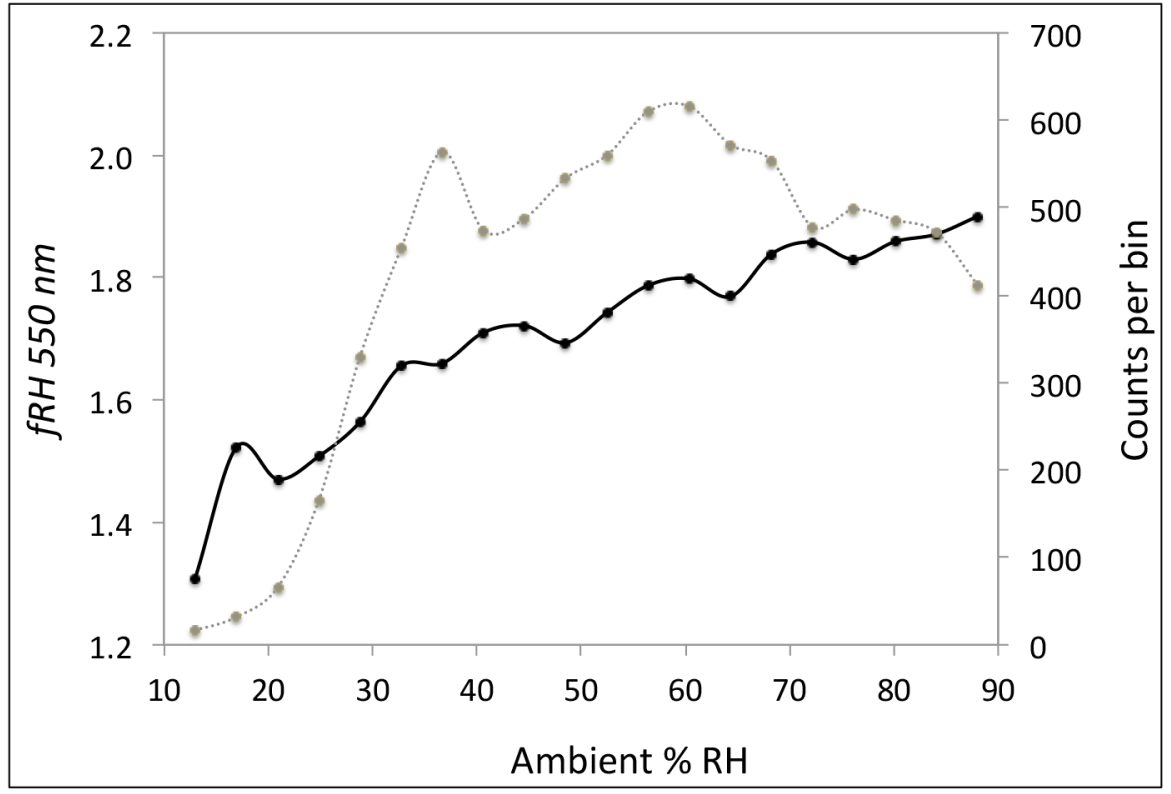

Figure 6. $f R H(85 \% / 40 \%)$ for sub $10 \mathrm{um}$ data binned by the ambient RH (solid line) and the binned probability distribution of the ambient RH (dashed line).

\subsection{Instrument RH and aerosol phase change}

The lowest instrument RH prior to hydration will affect the aerosol phase, whether it remains liquid, becomes more viscose or solid. For a mostly inorganic aerosol, the RH scattering growth behavior will move to the lower branch of the hysteresis curve if the humidifier RH drops below the efflorescence RH. The lowest RH in the system prior to humidification is in the internal dry nephelometer which ranges from 5 to $60 \% \mathrm{RH}$ for the hygroscopic fits that meet the fit criteria. The internal instrument $\mathrm{RH}$ varies with the ambient dew point. Dew point values at SGP vary from as low as $-20 \mathrm{C}$ in the winter to values as high as $26 \mathrm{C}$ in the summer. Over the summer when high dew points are prevalent, SGP aerosol consists of mostly low-volatility, highly oxidized organic species (Parworth et al., 2015). As such, the summer aerosol is likely invariant to changes in the sampling RH for an instrument RH above $\sim 30 \%$. However, during the cold winter months, the sampling RH can drop below the efflorescence RH of most inorganic salts. Figure 7 shows a graph of binned $f R H$ and SMF versus the dry nephelometer RH. Note that $98 \%$ of the data that met the fit conditions were when the dry nephelometer $\% \mathrm{RH}<50 \%$. Both $f R H$ 
and the SMF increase at dry nephelometer $\mathrm{RH}$ values greater than $50 \%$. These times are infrequent but are typical of high dew points during the summer daytime. The increase in $f R H$ at high sampling RH possibly indicates a phase transition, but may also reflect daytime photochemical production of aerosol sulfate and oxidized organics.

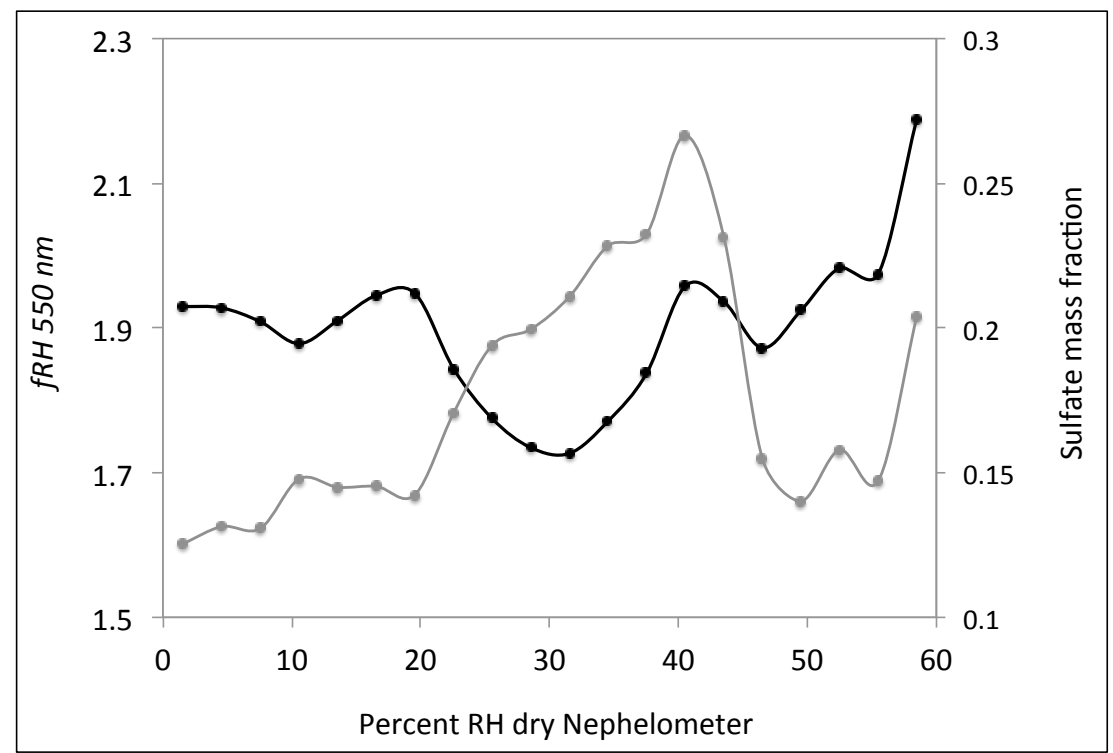

Figure 7. $f R H$ (solid line) and the SMF (gray line) binned by the dry nephelometer RH.

Martin et al. [2008] measured the aerosol phase activity with RH of $150 \mathrm{~nm}$ particles at SGP. They found deliquescence in $13 \%$ of their humidifier scans. Approximately $\sim 30 \%$ of the $150 \mathrm{~nm}$ particles in these 13 scans exhibiting a phase change at $\sim 80 \% \mathrm{RH}$, similar to that of $\left(\mathrm{NH}_{4}\right)_{2} \mathrm{SO}_{4}$. With only a fraction of the particles exhibiting deliquescent behavior their finding denotes an externally mixed aerosol in these air samples. In another study, closure measurements of nephelometer $f R H$ with aerosol diameter hygroscopic growth, $g R H$, at SGP (Gasparini et al., $2006 a$ ) indicated that the sampled nephelometer aerosol was more metastable than crystalline. In general, the predicted $f R H$ was within 0.15 the measured values, with the measured $f R H$ values usually lower that those calculated from $g R H$. A step change in aerosol scattering with $\mathrm{RH}$ is difficult to observe over a broad size range of scattering measurements, especially if the aerosol is externally mixed with a lesser fraction of deliquescent aerosol. A lower fit quality with decreasing ambient RH is expected if the growth behavior doesn't fit the expected algorithms of a metastable aerosol. However no RH dependence of the chi-square goodness of fit parameter was observed for the 2 fit algorithms.

Another indication of aerosol phase or viscosity change is a deviation of the $f R H$ data from the fit algorithm with RH. Such an analysis necessitates a high scattering signal with low noise and so biases the data to times with high aerosol loading. Zhang et al. [2015] introduce a steepness parameter that evaluates changes in the fit derivative at two $\mathrm{RH}$ values. A more robust comparison using the gamma algorithm compares the slope of a fit line from $\sim 40-60 \% \mathrm{RH}$ to the power law fit parameter $\gamma$. For an ideal fit this ratio is $\sim-2$. A ratio $>-2$ indicates a much lower slope or slower increase with $\mathrm{RH}$ at low $\mathrm{RH}$ compared to a fit of the full range of RH. A similar comparison with the kappa algorithm involves a comparison of $\kappa_{s c a}$ over the entire RH range to the fit slope for $\mathrm{RH}>65 \%$. Figure 8 shows an example of the two fit comparisons. The RH range 
of each fit was optimized to exploit the changes in growth behavior with RH. A significant increase in the slope at higher RH may indicate a change in phase or viscosity. Phase change analysis using ratios over different $\mathrm{RH}$ ranges are nuanced and depend on the chosen $\mathrm{RH}$ range, goodness of fit and fit algorithm. Size dependence of the aerosol scattering efficiency as well as size-dependent transmission losses can result in an apparent decrease in scattering growth with RH. Further corroboration of this method with aerosol composition and size-dependent hygroscopic growth would be useful. More distinct phase transition behavior is expected at sites with higher inorganic composition. Though simple, this ratio technique works well in identifying broad trends in the aerosol phase behavior for a large data set. Rather than a binary view of the aerosol as being on an upper or lower branch of a phase hysteresis, the method allows for a continuum of phase behavior present in externally mixed aerosol.

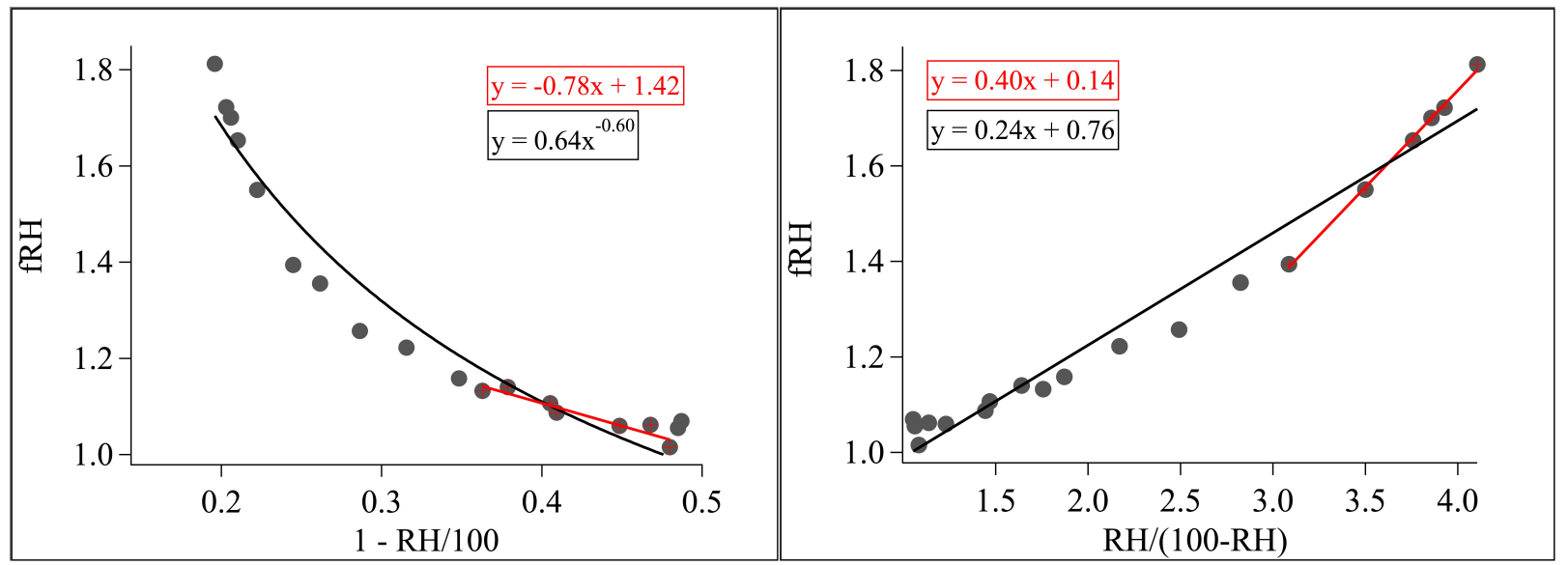

Figure 8. Plots of Gamma (left) and Kappa (right) hygroscopic growth fits. Red lines are linear fits of the data over a limited RH range. Data from sub um aerosol scattering coefficients at 550nm on April 27, 2014 at SGP. Fit equation boxes are colored the same as the corresponding fit line.

\section{Discussion}

Long-term measurements probe large-scale processes that span seasons and years. Statistical analysis of these large data sets shows systematic relationships between variables over a range of conditions that then illuminate feedbacks between the boundary layer, hydrologic, radiation and aerosol cycles. The covariances and trends conceptualize atmospheric aerosol dynamics in broad terms that help us intuit this forcing. Though often qualitative, the empirical relationships place boundaries on remote sensing retrievals and climate models. Although the $f R H$ measurements presented here show distinct trends and variances, the uncertainty and possible phase transitions associated with these measurements place limits around the scope of their use. Locations with low aerosol loading or low dew point need high scrutiny. The intent of the analysis presented here is to optimize $f R H$ data use in evaluation of remote sensing and model products.

Statistically, the two algorithms presented, kappa and gamma, had comparable fit uncertainties over the range of the entire data set. For an individual humidifier scan one fit may perform better than the other with respect to a high or low RH range or steepness of the scattering growth with 
RH. In general, the two algorithms fit the hygroscopic growth behavior well with relatively low chi-square goodness of fit values over a broad range of aerosol scattering values. The uncertainty calculations are for a generic hydration scan and don't account for calibration errors or other instrument-specific error outside of normal operating conditions. Such circumstances need an individual evaluation of measurement error. Signal noise from the aerosol scattering coefficients is the largest contributor to the fit error such that scattering values less than $10 \mathrm{Mm}^{-1}$ may not yield reasonable values of gamma or kappa. Reduction of scattering coefficient noise can be achieved by performing hour-long scans with a 2-minute average of the data. This comes with a reduction in temporal resolution and increased risk of the air mass and aerosol properties changing over the measurement period. For sites with low aerosol loading and little air mass variability the longer scan time will reduce the fit error.

Alternatively, the fit parameters can be approximated from known cross correlations with aerosol optical and/or chemical properties. As long-term aerosol scattering hygroscopic growth measurements are sparse, these cross correlations of the fit parameters with more common in-situ measurements of aerosol optical properties will enhance the global coverage of aerosol $f R H$. Large aerosol observation networks such as the NOAA federated network (www.esrl.noaa.gov/gmd/aero), ACTRIS (www.actris.net) and DOE ARM (www.arm.gov) provide long-term measurements of aerosol optical properties for such analysis.

Aerosol $f R H$ at SGP has a strong seasonal variance, driven mostly by changes in the aerosol chemistry. Higher winter values are attributed to a high NMF that results from a low nitric acid vapor pressure at colder temperatures. The lower summer time $f R H$ values accompany a higher OMF. Despite changes in the predominant transport sector with season, $f R H$ exhibited little variation with wind sector for a given season. This suggests that local aerosol emissions and/or similar, sector-independent processes such as photochemical oxidation, cloud processing and temperature-dependent vapor pressures, regulated the aerosol hygroscopic growth behavior for a given season. The average $f R H$ values reported here are comparable to median values reported by Sheridan et al. (2001) from SGP of 1.83 (sub $10 \mathrm{um}$ ) and 1.86 (sub $\mathrm{um}$ ). The lower sub $10 \mathrm{um}$ $f R H$ values may indicate an influence from dust. For comparison, $f R H$ measurements from other rural regions in the Western U.S. report values that range from as low as 1.26 in California (Malm et al., 2005) to as high as 2.06 in Texas (Malm et al., 2003).

Strong correlations between the aerosol hygroscopic growth, chemistry and optical properties indicate these properties are closely coupled. Changes in $f R H$ associated with optical and chemical properties suggest that larger, less absorbing, more oxidized particles with a lower OMF have a higher hygroscopic growth. This behavior isn't necessarily repeated for larger particles that may include coarse mode dust, a higher organic fraction or aerosols large enough for their scattering efficiency to decline at $550 \mathrm{~nm}$ with increased growth. The aerosol $f R H$ showed opposing behavior with BSF and SAE, with increased water uptake with size for smaller accumulation mode aerosol (BSF) and decreased water uptake with size for larger accumulation and coarse mode particles (SAE). These correlations with aerosol optical and chemical properties can be used to constrain the hygroscopic fit parameter when $f R H$ measurements are not present, the fit quality is low or the aerosol scattering values are too low to give a reliable fit parameter. The correlations are specific to SGP but may be extended to regions with similar aerosol type and climate. 
Aerosol phase spans the range of a liquid solution to a viscous, amorphous liquid to a mixed phase aerosol with solid inclusions to a solid. These phases can vary with aerosol size and between internally and externally mixed particles. Trends in the hygroscopic growth fit parameter with large differences between the dry sample and ambient RH were ambiguous and neither support nor discount sampling-induced changes in aerosol phase. Phase shift behavior, as observed from scattering hygroscopic growth measurements, is subtle for an aged, mostly organic aerosol. Distinct discontinuity in the humidification scans won't be observed unless a large enough fraction of the optically active aerosol deliquesces. We present 2 methods which ratio the scattering growth behavior over differing $\mathrm{RH}$ ranges to infer a phase change. The methods are qualitative and limit analysis to data with low noise. Unlike detailed closure measurements, this ratio method is an effective tool to gauge changes in aerosol phase when evaluating a large data set.

Much more can be accomplished with this data set and similar data sets of the RH-dependent aerosol scattering behavior in the DOE ARM archive. Extensions of this study are to repeat the analysis for other sites and aerosols types such as marine, smoke, pollution, and forested regions and a comparison of in-situ surface measurements of aerosol extinction $f R H$ with RH-dependent retrievals from remote sensing measurements. Decoupling the aerosol optical properties from the ambient RH can improve the remote sensing retrievals as well as radiative forcing model parameterizations.

\section{Acknowledgements}

The authors acknowledge support by the U.S. Department of Energy Atmospheric Radiation Measurement Program via Argonne National Laboratory. The authors would like to thank the DOE SGP ARM Climate Research Facility staff and scientists who helped maintain the instruments and ingest the data used for this paper, particularly Patrick Dowell, Ken Teske, Matt Gibson, Annette Koontz and Connor Flynn. In-situ aerosol optical measurement data is available from the DOE ARM archive at https://www.arm.gov/data. 


\section{References}

Anderson, T. L. and Ogren, J. A. (1998), Determining aerosol radiative properties using the TSI 3563 integrating nephelometer, Aerosol Sci. Tech., 29, 57-69.

Anderson, T. L., Covert, D. S., Wheeler, J. D., Harris, J. M., Perry, K. D., Trost, B. E., Jaffe, D. J., and Ogren, J. A. (1999), Aerosol backscatter fraction and single-scattering albedo:

Measured values and uncertainties at a coastal station in the Pacific Northwest, J. Geophys. Res., 104, 26793-26807, doi:10.1029/1999JD900172.

Barnard, J. C., Volkamer, R., and Kassianov, E. I. (2008), Estimation of the mass absorption cross section of the organic carbon component of aerosols in the Mexico City metropolitan area, Atmos. Chem. Phys., 8, 6665-6679, 2008, doi:10.5194/acp-8-6665-2008.

Bar-Or, R.Z., I. Koren, O. Altaratz, E. Fredj (2012), Radiative properties of humidified aerosols in a cloudy environment, Atmospheric Research 118, 280-294.

Beyersdorf, A.J., L. D. Ziemba, G. Chen, C. A. Corr, J. H. Crawford, G. S. Diskin, R. H. Moore, K. L. Thornhill, E. L.Winstead, and B. E. Anderson (2016), The impact of aerosol loading, composition, and water uptake on aerosol extinction variability in the Baltimore-Washington, D.C. region, Atmos. Chem. Phys., 16, 1003-1015, doi:10.5194/acp-16-1003-2016.

Bond, T. C., Anderson, T. L., and Campbell, D. (1999), Calibration and inter-comparison of filter-based measurements of visible light absorption by aerosols, Aerosol Sci. Tech., 30, 582-600,15 doi: $10.1080 / 027868299304435$.

Brock, C. A., N. L. Wagner, B. E. Anderson, A. R. Attwood, A. Beyersdorf, P. Campuzano-Jost, A. G. Carlton, D. A. Day, G. S. Diskin, T. D. Gordon, J. L. Jimenez, D. A. Lack1, J. Liao, M. Z. Markovic1, A. M. Middlebrook, N. L. Ng, A. E. Perring, M. S. Richardson, J. P. Schwarz, R. A. Washenfelder, A. Welti, L. Xu, L. D. Ziemba, and D. M. Murphy (2016), Aerosol optical properties in the Southeastern United States in summer -Part 1: Hygroscopic growth, Atmos. Chem. Phys., 16, 4987-5007, doi:10.5194/acp-164987-2016.

Carrico, C. M. and M. J. Rood (1998), Aerosol light scattering properties at Cape Grim, Tasmania during the first Aerosol Characterization Experiment (ACE 1), J. Geophys. Res., 103, 16565-16574.

Covert, D. S., R. J. Charlson and N.C. Ahlquist (1972), A study of the relationship of chemical composition and humidity to light scattering by aerosols, J. Appl. Meteor., 11, $968-976$.

Dassios, K. G., and S. N. Pandis (1999), The mass accommodation coefficient of ammonium nitrate aerosol, Atmos. Environ., 33, 2993-3003.

Fierz-Schmidhauser, R., Zieger, P., Wehrle, G., Jefferson, A., John A. Ogren, Urs Baltensperger and E. Weingartner (2010), Measurement of relative humidity dependent, light scattering of aerosols, Atmos. Meas. Tech. Discuss., 3,39-50.

Gasparini, R., Collins, D.R., Andrews, E., Sheridan, P. J., Ogren, J. A., and J. G. Hudson (2006a), Coupling aerosol size distributions and size-resolved hygroscopicity to predict humidity-dependent optical properties and cloud condensation nuclei spectra, , J. Geophys. Res., 111, D05S13, doi:10.1029/2005JD006092. 
Gasparini, R., Li, R. , Collins, D.R. , Ferrare, R. A., and V. G. Brackett (2006b), Application of aerosol hygroscopicity measured at the Atmospheric Radiation Measurement Program's Southern Great Plains site to examine composition and evolution, J. Geophys. Res., 111, D05S12, doi:10.1029/2004JD005448.

Gasso, S., Hegg, D.A., Covert, D.S., Collins, D., Noone, K. J., Öström, E., Schmid, B., Russell, P. B., Livingston, J. M., Durkee, P. A., and H. Jonsson (2000), Influence of humidity on the aerosol scattering coefficient and its effect on the upwelling radiance during ACE-2, Tellus, 52B, 546-567.

Gund, G., Wien, F. \& Weisweiler, W. Fresenius (1991), Oxidation of $\mathrm{SO}_{2}$ to sulfate in sea salt aerosols, J Anal Chem, 340: 616. doi:10.1007/BF00321522

Heintzenberg, J., A. Wiendensohler, T. M. Tuch, D.S. Covert, P. Sheridan, J. A. Ogren R. Nessler, C. Kleefeld, N. Kalivitis, V. Aatonen, R. T. Wilhelm and M. Havlicek (2006), Intercomparisons and aerosol calibrations of 12 commercial integrating nephelometers of three manufacturers, J. Atmos. and Oceanic Tech., 23, 902-914.

Jefferson, A (2010), Empirical estimates of CCN from aerosol optical properties at four remote sites. Atmos. Chem. Phys., 10 (14) 6855-6861, issn: 1680-7316, ids: 633PL, doi: 10.5194/acp-10-6855-2010.

Jing, B., Peng, C., Wang, Y., Liu, Q., Tong, S., Zhang, Y. , and Ge, M. (2017), Hygroscopic properties of potassium chloride and its internal mixtures with organic compounds relevant to biomass burning aerosol particles, Nature, doi: 10.1038/srep43572.

Kasten, F.(1969), Visibility forecast in the phase of pre-condensation, Beitr. Phys. Atmos., 41, 631-635.

Kuang, Y., C.S. Zhao, J. C. Tao, Y. X. Bian, N. Ma, and G. Zhao (2017), A novel method to derive the aerosol hygroscopicity parameter based only on measurements from a humidified nephelometer system, Atmos. Chem. Phys., doi:10.5194/acp-2016-1066.

Kennedy, A. D., X. Q. Dong, B. K. Xi, P. Minnis, A. D. Del Genio, A. B. Wolf, and M. M. Khaiyer, (2010), Evaluation of the NASA GISS single-column model simulated clouds using combined surface and satellite observations. J. Climate, 23, 5175-5192, doi: 10.1175/2010JCLI3353.1

Kinne, S., M. Schulz, C. Textor, S. Guibert, Y. Balkanski, S. E. Böauer, T. Berntsen, T. F. Berglen, O. Boucher, M. Chin,W. Collins, F. Dentener, T. Diehl, R. Easter, J. Feichter, D. Fillmore, S. Ghan, P. Ginoux, S. Gong, A. Grini, J. Hendricks, M. Herzog, L. Horowitz, I. Isaksen, T. Iverson, A. Kierkevåg, S. Kloster, D. Koch, J. E. Kristjansson, M. Krol, A. Lauer, J. F. Lamarque, G. Lesins, X. Liu, U. Lohmann, V. Montanaro, G. Myhre, J. E. Penner, G. Pitari, S. Reddy, O. Seland, P. Stier, T. Takemura and X. Tie (2006), An AeroCom initial assessment - optical properties in aerosol component modules of global models, Atmos. Chem. Phys., 6, 1815-1834.

Kotchenmther, R. A., P. V. Hobbs, and D. A. Hegg (1999), Humidification factors for atmospheric aerosols off the mid-Atlantic coast of the United States, J. Geophys. Res., 104, 2239-2251.

Lack, D. A. and C. D. Cappa (2010), Impact of brown and clear carbon on light absorption enhancement, single scatter albedo and absorption wavelength dependence of black carbon, Atmos. Chem. Phys.,10,2074220, doi:10.5194/acp-10-4207-2010. 
Lewandowski, M. , Jaoui, M , Offenberg, J.H., Krug, J. D., and T. E. Kleindienst (2015), Atmospheric oxidation of isoprene and 1,3-butadiene: influence of aerosol acidity and relative humidity on secondary organic aerosol Atmos. Chem. Phys., 15, 3773-3783, doi:10.5194/acp-15-3773-2015.

Lewis, E. R. and S. E. Schwartz (2004), Sea Salt Aerosol Production: Mechanisms, Methods, Measurements, and Models, Washington, D.C., American Geophysical Union, Section 2.5.3.

Lighthouse, J. M., Onasch, T. B. and D. Imre (2000), Deliquescence, efflorescence, and water activity in ammonium nitrate and mixed ammonium nitrate/succinic Acid microparticles, J. Phys. Chem. A, 104, 9337-9346.

Malm, W.C., Day, D.E., Kreidenweis, S.M., Collet, J.L., and Lee, T., (2003). Humidity-dependent optical properties of fine particles during the Big Bend regional aerosol and visibility observational study. J. Geophys. Res. 108 (D9), 4279.

Malm,W.C., Day, D.E., Kreidenweis, S.M., Collett Jr., J.L., Carrico, C.M., McMeeking, G., and Lee, T., (2005). Hygroscopic properties of an organic-laden aerosol. Atmos. Environ. 39, 4969e4982.

Marti, J. J., R.J. Weber, P.H. McMurry, F.L. Eisele, D.J. Tanner and A. Jefferson (1997) New particle formation at a remote continental site: Assessing the contributions of $\mathrm{SO}_{2}$ and organic precursors, $J$. Geophys. Res., 102, 6331.

Martin, S. T., Rosenoem, T., Chen, Q., and D.R. Collins (2008), Phase changes of ambient particles in the Southern Great Plains of Oklahoma, Geophys. Res. Lett., 35, L22801, doi: 10.1029/2008GL035650.

Massoli, P., Bates, T. S., Quinn, P. K., Lack, D. A., Baynard,T., Lerner, B. M., Tucker, S. C., Brioude, J., Stohl, A., and E. J. Williams, (2009) Aerosol optical and hygroscopic properties during TexAQS-GoMACCS 2006 and their impact on aerosol direct radiative forcing, J. Geophys. Res., 114, D00F07, doi:10.1029/2008JD011604.

Ogren, J. A. (2010) Comment on "Calibration and Intercomparison of Filter-Based Measurements of Visible Light Absorption by Aerosols", Aerosol Sci. Tech., 44, 589-591, 30

doi:10.1080/02786826.2010.482111.

Parworth, C., J. Fast, F. Mei, T. Shippert, C. Sivaraman, A. Tilp, T. Watson, and Q. Zhang (2015), Longterm measurements of submicrometer aerosol chemistry at the Southern Great Plains (SGP) using an Aerosol Chemical Speciation Monitor (ACSM), Atmospheric Environment, 106, 43- 55.

Paul, J. W. and B.J. Zebarth (1997), Denitrification and nitrate leaching during the fall and winter following cattle slurry application, Can. J. Soil Sci. 77: 231-240.

Pueschel, R. F., R. J. Charlson and N.C. Ahlquist (1969), On the anomalous deliquescence sea-spray aerosols, J. Appl. Meteor., 11, 995 -998.

Quinn, P. K., T. S. Bates, T. Baynard, A. D. Clarke, T. B. Onasch, W. Wang, M. J. Rood, E. Andrews, J. Allan, C. M. Carrico, D. Coffman,1 and D. Worsnop (2005), Impact of particulate organic matter on the relative humidity dependence of light scattering: A simplified parameterization, Geophys. Res. Lett., 32, L22809, doi:10.1029/2005GL024322.

Randles, C. A., L. M. Russell, and V. Ramaswamy (2004), Hygroscopic and optical properties of organic sea salt aerosol and consequences for climate forcing, Geophys. Res. Lett., 
31, L16108, doi:10.1029/2004GL020628.

Saide, P.E., J. Kim, C. H. Song, M. Choi, Y. Cheng, and G. R. Carmichael (2014), Assimilation of next generation geostationary aerosol optical depth retrievals to improve air quality simulations, Geophys. Res. Lett., 41, 9188-9196, doi:10.1002/2014GL062089.

Schuster, G. L., O. Dubovik, and B. N. Holben (2006), Angstrom exponent and bimodal aerosol size distributions, J. Geophys. Res., 111, D07207, doi:10.1029/2005JD006328.

Sheridan, P. J., D. J. Delene and J. A. Ogren (2001), Four years of continuous surface aerosol measurements from the Department of Energy's atmospheric measurement program Sothern Great Plains cloud and radiation testbed site, Geophys. Res.Lett.,106, 20735-20747.

Sheridan, P. J., W. P. Arnott, J. A. Ogren, E. Andrews, D. B. Atkinson, D. S. Covert, H. Moosmüuller, A. Petzold, B. Schmid, A. W. Strawa, R. Varma, and A. Virkkula (2005), The Reno Aerosol optics study: An evaluation of aerosol absorption measurement methods, Aer. Science and Tech., 39, 1-16, doi: $10.1080 / 027868290901891$.

Sherman, J. P., P. J. Sheridan, J. A. Ogren, E. A. Andrews, L. Schmeisser, A. Jefferson, and S. Sharma (2015), A multi-year study of lower tropospheric aerosol variability and systematic relationships from four North American regions, Atmos. Chem. Phys., 15, 12487-12517, 2015, doi:10.5194/acp-15-124872015.

Shinozuka, Y., A. D. Clarke, A. Nenes, A. Jefferson, R. Wood, C. S. McNaughton, J. Ström, P. Tunved, J. Redemann, K. L. Thornhill, R. H. Moore, T. L. Lathem, J. J. Lin, and Y. J. Yoon (2015), The relationship between cloud condensation nuclei $(\mathrm{CCN})$ concentration and light extinction of dried particles: indications of underlying aerosol processes and implications for satellite-based CCN estimates, Atmos. Chem. and Phys., 5, 7585-7604, doi:10.5194/acp-15-7585-2015

Skupin, A., A. Ansmann, R. Engelmann, P. Seifert, and T. Müller (2016), Four-year long-path monitoring of ambient aerosol extinction at a central European urban site: dependence on relative humidity, Atmos. Chem. Phys., 16, 1863-1876, doi:10.5194/acp-16-1863-2016.

Stelson, A. and Seinfeld, J.H. (1982), Relative humidity and $\mathrm{pH}$ dependence of the vapor pressure of ammonium nitrate-nitric acid solutions at 25C., Atmos. Environment, 16, 2507-2514.

Tang, I. N. (1980), Deliquescence Properties and Particle Size Change of Hygroscopic Aerosols. In Generation of Aerosols and Facilities for Exposure Experiments; Willeke, K., Ed.; Ann Arbor Science Pub. Inc.: Ann Arbor, MI, pp 153-165.

Textor, C. , M. Schulz, S. Guibert, S. Kinne, Y. Balkanski, S. Bauer, T. Berntsen, T. Berglen, O. Boucher, M. Chin, F. Dentener, T. Diehl, R. Easter, H. Feichter, D. Fillmore, S. Ghan, P. Ginoux, S. Gong, A.

Grini, J. Hendricks, L. Horowitz, P. Huang 1, I. Isaksen, T. Iversen, S. Kloster, D. Koch, A. Kirkevåg, J. E. Kristjansson, M. Krol1, A. Lauer, J. F. Lamarque, X. Liu, V. Montanaro, G. Myhre, J. Penner, G. Pitari, S. Reddy5, Ø. Seland, P. Stier, T. Takemura, and X. Tie (2006), Analysis and quantification of the diversities of aerosol life cycles within AeroCom, Atmos. Chem. Phys., 6, 1777-1813.

Titos, G., A. Jefferson, P. J. Sheridan, E. Andrews, H. Lyamani, L. Alados-Arboledas, and J. A. Ogren (2014), Aerosol light-scattering enhancement due to water uptake during the TCAP campaign, Atmos. Chem. Phys., 14, 7031-7043, doi:10.5194/acp-14-7031. 
Virkkula, A., Ahlquist, N. C., Covert, D. S., Arnott,W. P., Sheridan, P. J., Quinn, P. K., and Coffman, D. J. (2005), Modification, calibration and a field test of an instrument for measuring light absorption by particles, Aerosol Sci. Tech., 39:68-83.

Yang, Weidong, Alexander Marshak, Tamás Várnai, and Robert Wood (2014), CALIPSO observations of near-cloud aerosol properties as a function of cloud fraction, Geophys. Res.Lett., 41, 9150-9157, doi:10.1002/ 2014GL061896.

Zhang, L., J.Y. Sun, X.J. Shen, Y. M. Zhang, H. C. Che, Q. L. Ma, Y. W. Zhang, X. Y. Zhang and J. A. Ogren (2015), Observations of relative humidity effects on aerosol light scattering in the Yangtze River Delta of China, Atmos. Chem. Phys., 15, 8439-8454, doi:10.5194/acp-15-8439-2015.

Zhang, X., A. Hecobian, M. Zheng, N. H. Frank, and R. J. Weber (2010), Biomass burning impact on PM2.5 over the southeastern US during 2007: integrating chemically-speciated FRM filter measurements, MODIS fire counts and PMF analysis, Atmos. Chem. Phys., 10, 6839-6853, doi:10.5194/acp-10-68392010.

Ziemba L. D., K. Lee Thornhill, R. Ferrare, J. Barrick, A. J. Beyersdorf, G. Chen, S. N. Crumeyrolle, J. Hair, C. Hostetler, C. Hudgins, M. Obland, R. Rogers, A. J. Scarino, E. L. Winstead, and B. E. Anderson (2013), Airborne observations of aerosol extinction by in situ and remote-sensing techniques: Evaluation of particle hygroscopicity, Geophys. Res. Lett., 40, 417-422, doi:10.1029/2012GL054428.

Zieger, P., R. Fierz-Schmidhauser, E.Weingartner, and U. Baltensperger (2013), Effects of relative humidity on aerosol light scattering: results from different European sites, Atmos. Chem. Phys., 13, 10609-10631, doi:10.5194/acp-13-10609. 